\title{
Should unemployment benefits be related to previous earnings?
}

\author{
Burkhard Heer * \\ Free University of Bolzano-Bozen and CESifo
}

Final Version for Finanzarchiv: September 12, 2006

JEL classification: J65, J64, E60, E62

Key Words: Earnings-related Unemployment Benefits, Hartz IV, Computable General Equilibrium, Overlapping Generations

\begin{abstract}
:
In most OECD countries, unemployment benefits are tied to individual previous labor earnings. We study the progressivity of this indexation in a calibrated general equilibrium overlapping-generations model with flexible labor supply keeping the government expenditures on unemployment insurance constant over the different scenarios. We find that higher indexation of unemployment benefits to previous earnings has only small quantitative effects on output, employment, the distribution of income, and welfare. We also provide a tentative analysis of the most recent Hartz IV reform, where unemployment benefits decrease sharply after one year of unemployment. This reform is found to have positive but very small efficiency and welfare effects.

\footnotetext{
${ }^{*}$ Corresponding address: Free University of Bolzano-Bozen, School of Economics and Management, Via Sernesi 1, 39100 Bolzano, Italy, email: Burkhard.Heer@unibz.it

I would like to thank Alfred Maussner, Mark Trede, and two anonymous referees for their comments on earlier versions of this paper. All remaining errors are mine.
} 


\section{Introduction}

Unemployment insurance (UI) schemes are a distinctive feature of modern economies and have been frequently recognized to play an important role in determining labor market outcomes. The possible influence of the level and duration of unemployment benefits on unemployment and welfare has been given considerable attention in research. The general argument usually put forward is that unemployment benefits improve the payoff from not working and decrease the incentives to supply labor. Accordingly, recent work on the employment effects of unemployment benefits emphasizes the moral hazard associated with the job search effort of the unemployed, e.g. Hansen/İmrohoroğlu (1992) or Ljungqvist/Sargent (1998), the moral hazard associated with the job retention effort, e.g. Wang/Williamson (1996), and the direction of search effort to high wage jobs, e.g. Burdett (1979), Acemoglu (2001), Acemoglu/Shimer (1999), or Marimon/Zilibotti (1997). In addition, Shavell/Weiss (1979), Frederiksson/Holmlund (2001), and Heer (2002a,2003) emphasize the fact that the duration period of most unemployment insurance programs are limited and find that UI benefits should, optimally, decline over time.

The literature discussed in the preceding paragraph, however, considers the level of benefits to be lump-sum. In most OECD countries, unemployment benefits consist of both unemployment insurance and unemployment assistance. ${ }^{1}$ Most often, as e.g. in Belgium, France, Germany, or the US, unemployment insurance payments are related to past contributions and compensate for a loss of income for a limited duration. Afterwards, unemployed agents rely on unemployment assistance which is usually lower than unemployment insurance and most often unrelated to past contributions, e.g. in France, Germany after the Hartz IV reform, or the UK. Furthermore, most countries provide a minimum unemployment income (often in the form of social assistance or welfare payments) and unemployment benefits are only paid up to a certain level, e.g. in Belgium, Spain, or Japan. Consequently, unemployment benefits in practice contain both a lump-sum component and a component that

\footnotetext{
${ }^{1}$ For the features of the different UI schemes in practice see $\operatorname{OECD}(1991,1996)$.
} 
is proportional to previous unemployment contributions.

Different from the literature cited in the first paragraph of this introduction, we consider a model with unemployment benefits that depend on previous labor earnings. Therefore, the worker also considers the effect of his working hours on potential future unemployment benefits when he chooses his labor supply. The employment status of the worker follows an exogenous Markov process that is calibrated with regard to the characteristics of the German economy. In addition, we distinguish several productivity types so that we are able to model the wage heterogeneity and the wage-age profile of the German economy as well as the wage mobility of the German workers. Moreover, we endogenize the financing of the unemployment insurance payments. In particular, we consider the case that total government expenditures on unemployment compensation are constant for all cases considered and are to be financed by unemployment insurance contributions. As a consequence, an increase of the part of unemployment insurance benefits that is proportional to past earnings results in a decrease of the lump-sum part of unemployment insurance benefits that is unrelated to previous earnings.

There are multiple effects of a more progressive indexation of unemployment benefits to previous earnings on equilibrium values of employment, savings, output, and the distribution of labor income: 1) The worker considers the likelihood to become unemployed in the next period in his labor supply decision and, therefore, his incentives to supply labor increase if unemployment benefits are stronger linked to previous earnings. 2) Higher indexation of unemployment benefits to previous earnings with a compensating decrease of the lump-sum component results in higher (lower) benefits for the unemployed workers with previously high (low) labor income. Consequently, a more contributive unemployment insurance scheme redistributes income from the unemployed low-productivity workers to the unemployed high-productivity workers. As earnings peak around age 50, such a scheme also redistributes income from the young unemployed workers to the old unemployed workers. The redistribution is likely to also affect aggregate savings. The high-productivity (low-productivity) unemployed workers will increase (reduce) savings when their wage re- 
placement income increases (decreases). Since the high-productivity workers have a higher propensity to save out of income than the low-productivity workers, ${ }^{2}$ this effect is likely to increase savings. However, the high-productivity (low-productivity) employed workers will also reduce (increase) their precautionary savings. The overall effect on savings, therefore, cannot be determined analytically. For this reason, we use a general equilibrium model that is calibrated with regard to the characteristics of the German economy in 1991-97.

In addition to the equilibrium effects on savings, labor supply, and the distribution of labor income, we also study the welfare implications of a more progressive unemployment benefit scheme. Again, there are multiple effects: First, labor replacement income is redistributed from the low-productivity to the high-productivity workers. As we will measure welfare by average utility we need to compare the respective gains and losses of the different unemployed workers. Second, there are efficiency effects as aggregate savings and total labor supply change. Third, a more contributive system increases uncertainty as labor income (including replacement income) becomes more variable. Our welfare analysis, therefore, is related to the recent literature on the effects of a consumption tax versus an income tax, e.g. Nishiyama and Smetter (2005), that emphasizes the insurance properties of various tax schemes and contrast them with the efficiency and distribution effects. ${ }^{3}$

The paper is organized as follows. Section 2 introduces the model and discusses our calibration. Our results are presented in section 3. First, we analyze the effects of higher indexation assuming that government expenditures on unemployment benefits are constant. Second, we also study the most recent Hartz IV reform that reduces benefit payments to the long-term unemployed. In this case, government expenditures on unemployment insurance fall. Section 4 concludes. The computational method is described in the Appendix.

\footnotetext{
${ }^{2}$ This empirical regularity is documented by Huggett and Ventura (2000), among others. They also show that a model with earnings differences and a social security system, which is similar to ours, is able to replicate these facts.

${ }^{3}$ We would like to thank an anonymous referee for pointing this out to us. Different from this problem of optimal taxation, however, a reform of the unemployment insurance system only redistributes income between different groups of workers and not between workers and retired agents.
} 


\section{The Model}

We study an Overlapping Generations (OLG) model with income uncertainty. Three sectors can be depicted: the household sector, the production sector, and the government. Households live for 60 years and maximize discounted life-time utility. Agents can either be employed or unemployed during their working life. If employed, workers supply labor elastically. Individuals are heterogeneous with regard to their income productivity and cannot insure against idiosyncratic income risk. Firms maximize profits and produce output with the help of labor and capital. The government provides social insurance which it finances by a tax on wage income (or, equally, unemployment insurance contributions). Since we will only analyze steady-state allocations, the time index is omitted from stationary variables like, e.g., from the interest rate $r$ or the wage rate $w$.

\section{$2.1 \quad$ Households}

Agents live for $T+T^{R}=60$ periods (60 years). The first $T=40$ periods (40 years), they are workers. The last $T^{R}=20$ periods of their life, they retire and receive pension payments $b$. Households are of measure one and each generation is of equal measure 1/60. Households are heterogeneous with regard to their age $j$, their productivity type $z$, and their wealth $k .{ }^{4}$ We assume the individual productivity type $z$ to take a value from the finite set $\mathcal{Z}=\left\{z^{1}, z^{2}, \ldots, z^{n_{z}}\right\}$, where $z^{1}=0$ describes the state of unemployment. We further assume that the productivity type follows a first order finite state Markov chain

\footnotetext{
${ }^{4}$ As we only consider one type of asset, we will refer to $k$ as capital, wealth, and asset interchangeably.
} 
with conditional transition probabilities given by: ${ }^{5}$

$$
\pi\left(z^{\prime} \mid z\right)=\operatorname{Pr}\left\{z_{t+1}=z^{\prime} \mid z_{t}=z\right\}
$$

where $z^{\prime}$ denotes the next-period productivity type and $z, z^{\prime} \in \mathcal{Z}$. Individual productivity is a function of the productivity type and the age, $\epsilon=\epsilon(z, j)$.

The household maximizes his intertemporal utility:

$$
E \sum_{j=1}^{T+T^{R}} \beta^{j-1} u\left(c_{j}, 1-l_{j}\right)
$$

where instantaneous utility $u\left(c_{j}, 1-l_{j}\right)$ is assumed to be addititively separable in the utility from consumption, $c$, and the utility from leisure, $1-l$, as given by: ${ }^{6}$

$$
u\left(c_{j}, 1-l_{j}\right)=\frac{c_{j}^{1-\sigma}}{1-\sigma}+\gamma_{0} \frac{\left(1-l_{j}\right)^{1-\gamma_{1}}}{1-\gamma_{1}} .
$$

$l$ denotes the labor supply. The total time endowment is normalized to one. Instantaneous utility is discounted with the factor $\beta$, and $\sigma$ denotes the coefficient of relative risk aversion. If agents are unemployed or retired, they do not work $\left(l_{j}=0\right.$ for $z=z^{1}$ or $\left.j>T\right)$.

Agents are born without any assets, $k_{1}=0$, and are not allowed to borrow, $k_{j} \geq 0$, $j=1, \ldots, T+T^{R}$. Furthermore, we assume that private insurance markets are absent. ${ }^{7}$

\footnotetext{
${ }^{5}$ Notice that the Markov transition probabilities do not depend on age. With this simplification, we follow the traditional approach applied by the literature on dynamic general equilibrium in overlapping generations models with idiosyncratic uncertainty, e.g. as in Huggett and Ventura (2000). A more accurate, even though more demanding modelling device consists in the consideration and estimation of age-dependent Markov transition processes. We would like to thank an anonymous referee for bringing this to our attention.

${ }^{6}$ Our choice of the functional form for utility follows Castañeda, Díaz-Giminénez, and Ríos-Rull (2003). Most quantitative studies of general equilibrium model specify a Cobb-Douglas functional form of utility. In this case, however, the elasticity of individual labor supply with regard to wealth is larger than for the utility function (3) and, consequently, the distribution of both labor income and wealth that is implied by the model is much more homogeneous than in the data.

${ }^{7}$ Chiu and Karni (1998) show that the presence of private information about individual's work effort helps to explain the failure of the private sector to provide unemployment insurance.
} 
Depending on his employment type $z$, his previous labor income $\tilde{w}$, and his labor supply $l$, an agent at age $j$ receives labor income $y_{j}(z, \tilde{w}, l)$ and earns interest income at rate $r$ so that the household faces the following budget constraint:

$$
k_{j+1}+c_{j}=(1+r) k_{j}+y_{j}(z, \tilde{w}, l)
$$

where $k_{j+1}$ denotes next period's asset holdings. The labor income $y_{j}(z, \tilde{w}, l)$ of a $j$-year-old household with productivity type $z$, previous labor income $\tilde{w}$ and labor supply $l$ is given by:

$$
y_{j}(z, \tilde{w}, l)= \begin{cases}(1-\tau) w \epsilon(z, j) l & z>z^{1}, j \leq T, \\ w_{U I}(\tilde{w})=w_{\text {min }}+\theta(1-\tau) \tilde{w} & z=z^{1}, j \leq T, \\ b & j>T .\end{cases}
$$

If the worker is employed, $z>z^{1}$, he receives a wage rate that is proportional to his productivity $\epsilon(z, j)$. If unemployed, $z=z^{1}$, the worker receives unemployment benefits $w_{U I}$ which depend on his labor income $\tilde{w}=w \epsilon \cdot l$ during the last period that he was employed. If the agent has never been employed, $\tilde{w}=0$, the agent only receives $w_{\text {min }}$. Therefore, in our model, we can also interpret the lump-sum component $w_{\min }$ of unemployment benefits as welfare payments.

Let $\phi_{j}(k, \tilde{w}, z)$ and $l_{j}(k, \tilde{w}, z)$ denote the measure and the optimal labor supply of the $j$-year old household with wealth $k$, previous labor income $\tilde{w}$, and productivity type $z$. Effective labor $N$ in the economy equals the number of total working hours:

$$
N=\sum_{j=1}^{T} \sum_{z>z^{1}} \int_{k} \int_{\tilde{w}} \phi_{j}(k, \tilde{w}, z) \cdot \epsilon(z, j) \cdot l_{j}(k, \tilde{w}, z) d \tilde{w} d k
$$

The average effective labor supply $\bar{l}$ is equal to effective labor $N$ divided by the number of employed workers $n, \bar{l}=N / n$, with: 


$$
n=\sum_{j} \sum_{z>z^{1}} \int_{k} \int_{\tilde{w}} \phi_{j}(k, \tilde{w}, z) d \tilde{w} d k
$$

\subsection{Government}

The government uses the revenues from taxing labor in order to finance its expenditures on social security:

$$
\tau w N=\sum_{j} \int_{k} \int_{\tilde{w}} w_{U I}(\tilde{w}) \phi_{j}\left(k, \tilde{w}, z^{1}\right) d \tilde{w} d k+b n_{R}
$$

where $n_{R}=\frac{T^{R}}{T+T^{R}}$ denotes the fraction of retired agents.

The government policy is characterized by the set $\Omega=\left\{w_{\min }, \theta, \vartheta_{b}, \tau\right\}$, where $\vartheta_{b}=\frac{b}{(1-\tau) w l}$ denotes the replacement ratio of pensions $b$.

\section{$2.3 \quad$ Firms}

Firms are of measure one. They hire effective labor $N$ and capital $K$ in order to produce output $Y$ according to:

$$
Y=F(K, N)=K^{\alpha} N^{1-\alpha}
$$

In a market equilibrium, factors are compensated according to their marginal products and profits are zero:

$$
\begin{aligned}
& r_{t}=\alpha\left(\frac{N_{t}}{K_{t}}\right)^{1-\alpha}-\delta \\
& w_{t}=(1-\alpha)\left(\frac{K_{t}}{N_{t}}\right)^{\alpha},
\end{aligned}
$$

where $\delta$ denotes the depreciation rate of capital. 


\subsection{Stationary Equilibrium}

The concept of equilibrium applied in this paper uses a recursive representation of the consumer's problem following Stokey, Lucas, and Prescott (1989). Let $V_{j}(k, \tilde{w}, z)$ be the value of the objective function of a $j$-period old agent with beginning-of-period asset holdings $k$, previous income $\tilde{w}$, and employment type $z . V(k, \tilde{w}, z)$ is defined as the solution to the dynamic program:

$$
V_{j}(k, \tilde{w}, z)=\max _{c, k^{\prime}, l}\left[\frac{c^{1-\sigma}-1}{1-\sigma}+\gamma_{0} \frac{(1-l)^{1-\gamma_{1}}}{1-\gamma_{1}}+\beta E\left\{V_{j+1}\left(k^{\prime}, \tilde{w}^{\prime}, z^{\prime}\right)\right\}\right],
$$

subject to the budget constraint (4). The next-period value of previous labor income, $\tilde{w}^{\prime}$, is updated as follows:

$$
\tilde{w}^{\prime}= \begin{cases}\tilde{w} & z=z^{1} \\ w \cdot \epsilon(z, j) \cdot l_{j}(k, \tilde{w}, z) & z>z^{1} .\end{cases}
$$

In the first period of life, $j=1$, agents have no previous labor income, $\tilde{w}=0$.

\section{Definition}

A Stationary Equilibrium for a given distribution of productivities for the new-born generation, $\phi_{1}(0,0, z), z \in \mathcal{Z}$, and a given set of government policy parameters,

$\Omega=\left\{w_{\min }, \theta, \vartheta_{b}, \tau\right\}$, is a collection of value functions $V_{j}(k, \tilde{w}, z)$ of the households, individual policy rules for consumption, $c_{j}(k, \tilde{w}, z)$, labor supply, $l_{j}(k, \tilde{w}, z)$, and next-period wealth, $k_{j}^{\prime}(k, \tilde{w}, z)$, age-dependent, time-invariant measures of agent types $\phi_{j}(k, \tilde{w}, z)$ for each age $j=1,2, \ldots, T+T^{R}$, relative prices of labor and capital $\{w, r\}$, such that:

1. Factor inputs and consumption are otained aggregating over households:

$$
\begin{aligned}
C & =\sum_{z, j} \int_{k} \int_{\tilde{w}} c_{j}(k, \tilde{w}, z) \phi_{j}(k, \tilde{w}, z) d \tilde{w} d k, \\
K & =\sum_{z, j} \int_{k} \int_{\tilde{w}} k \phi_{j}(k, \tilde{w}, z) d \tilde{w} d k .
\end{aligned}
$$

Effective labor $N$ is given by (6). 
2. Given relative prices $\{w, r\}$ and the government policy $\Omega$, the individual policy rules $c(),. l($.$) , and k^{\prime}($.$) solve the consumer's dynamic program (12).$

3. Firms maximize profits. Factor prices (10) and (11) are equal to the factors' marginal productivities, respectively.

4. The goods market clears:

$$
K^{\alpha} N^{1-\alpha}=C+\delta K
$$

5. The government budget (8) is balanced.

6. The transition of the productivity types follows the first order Markov process (1).

\subsection{Calibration}

The steady state distribution of wealth and labor supply, and the effects of a change in the unemployment compensation system on employment and welfare cannot be studied analytically but only numerically. For this reason, the model is calibrated in order to match characteristics of the German economy after unification. The time series data refer to the period 1990-97. Time periods correspond to years. Data are mainly from the quarterly national account statistics of the German Institute for Economic Research (DIW), Berlin. The annual data on the unemployment rate is taken from the yearbooks of the German Statistical Office (Statistisches Bundesamt). Data on the wage and income distribution is taken from the Socio-Economic Panel for Germany (GSOEP).

\section{Households}

The coefficient of relative risk aversion $\sigma$ is set equal to 2.0. We choose the value 0.995 for household's discount factor $\beta$ implying an annual real interest rate equal to $2.83 \%$. The parameters $\gamma_{0}=0.13$ and $\gamma_{1}=10$ are taken from Heer and Trede (2003). For these values, the average labor supply of the workers amounts to 0.356 , while the coefficient of variation 
for the labor supply is equal to 0.363 . Heer and Trede estimate a coefficient of variation equal to 0.385 in Germany during 1995-96.

Productivity endowment is given by $\epsilon(z, j)=\bar{y}_{j} \cdot e^{z_{j}}$. The mean efficiency index $\bar{y}_{j}$ of the $j$-year old household is computed with the help of German data and graphed in figure 1. ${ }^{8}$ The productivity of age $j$ is computed with the help of the average hourly wages of the $j$-year old during the years 1990-97 following the method of Hansen (1993). Average productivity is normalized to one. We further interpolated the productivity-age profile with a polynomial function of order 3. Notice that the productivity-age profile is hump-shaped and peaks at age 47 .

Figure 1: Productivity-age profile in Germany, 1990-97

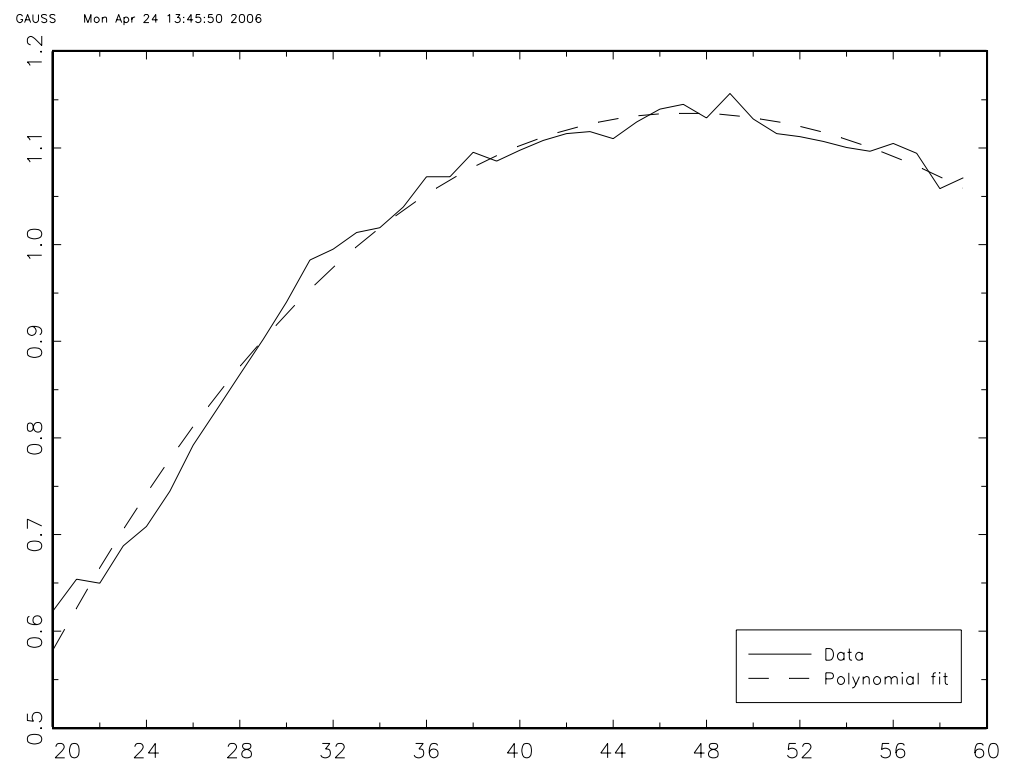

The productivities $z \in \mathcal{Z}=\left\{z^{1}, z^{2}, \ldots, z^{n z}\right\}$ and the transition matrix $\pi\left(z^{\prime} \mid z\right)$ are also taken from Heer and Trede (2003). The number of productivities is set equal to $n z=5$.

\footnotetext{
${ }^{8}$ We use data from the Cross National Data Files for West Germany during 1990-97 which are extracted from the GSOEP. I would like to thank Mark Trede for providing me with the data. We only consider agents who were working 1500 hours per year or more and who earned a wage in excess of one Euro. The number of observations for each generation ranges between 154 (for the 20-year old) and 765 (for the 29-year old).
} 
The productivities $\left\{z^{2}, z^{3}, z^{4}, z^{5}\right\}=\{0.4476,0.7851,1.0544,1.7129\}$ are estimated from the empirical distribution of hourly wages in Germany (1995). The unemployed worker has zero productivity, $z^{1}=0$. The transition matrix $\left(z^{\prime} \mid z\right)$ is chosen to model the German productivity mobility: ${ }^{9}$

$$
\pi\left(z^{\prime} \mid z\right)=\left(\begin{array}{ccccc}
0.3500 & 0.6500 & 0.0000 & 0.0000 & 0.0000 \\
0.0800 & 0.6751 & 0.1702 & 0.0364 & 0.0383 \\
0.0800 & 0.1651 & 0.5162 & 0.2003 & 0.0384 \\
0.0800 & 0.0422 & 0.1995 & 0.5224 & 0.1559 \\
0.0800 & 0.0371 & 0.0345 & 0.1606 & 0.6879
\end{array}\right)
$$

In the first period, we assume that unemployment amounts to average unemployment of $10.95 \%$ that prevails during the calibration period. The measures of the remaining four productivity classes in the first period are equal to each other, $\phi_{1}\left(0,0, z^{j}\right)=\frac{1-10.95 \%}{n z-1} \frac{1}{T+T^{R}}$, $j=2, \ldots, n z$.

\section{Government}

The government provides unemployment insurance and public pensions. In our benchmark case, the minimum unemployment insurance payments $w_{\min }$ are set equal to the welfare payments. In accordance with Heer (2003), the replacement ratios of welfare payments, $w_{\text {min }}$, and public pensions, $b$, are set equal to $30 \%$ and $50 \%$, respectively. The progressivity index $\theta=0.2$ is chosen in order to imply a replacement ratio of unemployment insurance roughly equal to $50 \% .{ }^{10}$ The income tax rate $\tau$ is calculated endogenously from

\footnotetext{
${ }^{9} \mathrm{We}$ assume that the worker can only reach productivity type $z^{2}$ after unemployment. This assumption is mainly for computational reasons. If we had assumed that the worker's human capital does not depreciate during unemployment and, therefore, that he would reach his old level of productivity when re-employed, we would have had to introduce an additional state variable into the model.

${ }^{10} \mathrm{We}$ also computed the equilibrium values for different values of the replacement ratio of welfare payments $(20 \%)$ and the replacement ratio of pensions $\left(\vartheta_{b}=40 \%\right)$. Our qualitative results are the same as in the benchmark case.
} 
Table 1: Calibration of parameter values for the German economy

\begin{tabular}{lll} 
Description & \multicolumn{1}{c}{ Function } & \multicolumn{1}{c}{ Parameter } \\
\hline utility function & $\frac{c^{1-\sigma}}{1-\sigma}+\gamma_{0} \frac{(1-l)^{1-\gamma_{1}}}{1-\gamma_{1}}$ & $\begin{array}{l}\sigma=2.0, \gamma_{0}=0.13, \\
\gamma_{1}=10\end{array}$ \\
& & $\beta=0.995$ \\
discount factor & $\beta$ & $\alpha=0.35$ \\
production function & $Y=K^{\alpha} N^{1-\alpha}$ & $\delta=0.04$ \\
depreciation & $\delta$ & $w_{\min } /(1-\tau) w \bar{l}=30 \%, \theta=0.20$ \\
$\begin{array}{l}\vartheta_{b} \equiv b /(1-\tau) w \bar{l}=50 \% \\
\text { pension payments }\end{array}$ & $b$ & \\
\hline
\end{tabular}

the government budget (8) and amounts to $23.0 \%$.

\section{Production}

In accordance with Heer (2003), the production elasticity of capital is set equal to $\alpha=0.35$, and the annual depreciation rate in Germany amounts to $\delta=0.04$.

\section{Results}

In this section, we study the effects of a more progressive indexation of unemployment benefits to previous wage income. First, we will describe the benchmark case which we are identifying with the German economy during 1990-97. Second, we analyze the effect of a change in the indexation of unemployment benefits that keeps total government expenditures on unemployment benefits constant. Finally, given the most recent reform of the unemployment insurance system in Germany, we also look at the effects of the Hartz IV reform that has changed the replacement ratio of unemployment benefits relative to net wages for the long-term unemployed workers. 


\subsection{The Benchmark Case}

Figure 2: Life-cycle profiles in the benchmark case
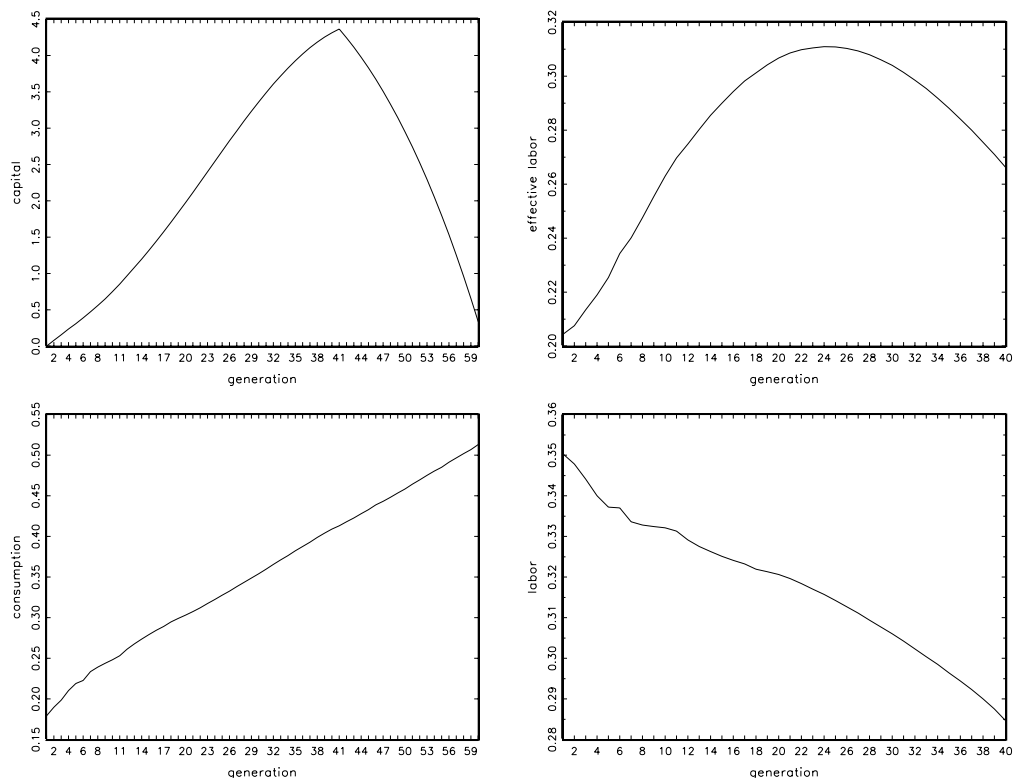

In our benchmark case that is calibrated with regard to the characteristics of the German economy during 1990-97, the lump-sum component of unemployment insurance benefits amounts to $30 \%$ of the average net wage, $w_{\min }=0.101$. The proportionality factor is set equal to $\theta=20 \%$. The equilibrium values of the capital stock $K$, effective labor $N$, average labor supply $\bar{l}$, the wage rate $w$, and the Gini coefficient of labor earnings Gini $i_{l}$ are presented in the third row of table 2. The aggregate capital stock and effective labor amount to $K=2.296$ and $N=0.186$, respectively. Average labor supply $\bar{l}$ is equal to 0.356 representing approximately one third of the available time endowment. The distribution of labor income (including the wage replacement income in the form of unemployment benefits) is characterized by a Gini coefficient equal to 0.335 which compares favorably with its empirical counterpart. Heer and Trede (2003) compute a Gini coefficient of labor income equal to 0.317 for the German economy using GSOEP data during 1995-96. 
Table 2: Effects of unemployment insurance indexation

\begin{tabular}{c|ccccccc}
\hline$\theta$ & $w_{\min }$ & $K$ & $N$ & $\bar{l}$ & $w$ & Gini $_{l}$ & $\Delta_{c}$ \\
\hline & & & & & & & \\
0.00 & 0.149 & 2.291 & 0.185 & 0.355 & 1.567 & 0.332 & $0.076 \%$ \\
0.20 & 0.101 & 2.293 & 0.186 & 0.356 & 1.566 & 0.335 & $0 \%$ \\
0.40 & 0.053 & 2.298 & 0.186 & 0.357 & 1.565 & 0.340 & $-0.048 \%$ \\
\hline
\end{tabular}

The behavior of the agents is typical for the one in life-cycle models. Figure 2 displays the averages of the capital stock, consumption, effective labor supply, and labor supply for each generation $j=1, \ldots, 60$ (the labor supply is zero for the generations $j=41, \ldots, 60$ ). Remember that generation $j=1$ corresponds to the 20 -year old households. The wealthage profile is hump-shaped and peaks at the age of retirement. Consumption is increasing over age. ${ }^{11}$ Effective labor, which is the product of hours worked times productivity, is hump-shaped and peaks at real lifetime age 42 (corresponding to the period 23 in the model). Accordingly, effective labor peaks prior to age productivity which attains its maximum at age 47 (compare figure 1). As can be seen from the lower right panel of figure 2 , average labor supply decreases over lifetime as agents become wealthier and, therefore, effective labor supply starts to fall earlier than average productivity. In figure 3 , the average labor supply of the employed workers is illustrated for the different productivities. The agents with the highest productivities, $z=z^{5}$, supply the highest amount of labor as in our model the substitution effect of higher wages per hour dominates the income effect.

\subsection{Progression of Unemployment Benefits}

In this section, we consider the effect of an increase of the progressivity of unemployment benefits $w_{U I}$. In the following we will speak of a progressive unemployment insurance system if the payments $w_{U I}=w_{\min }+\theta(1-\tau) \tilde{w}$ are closely linked to previous contributions

\footnotetext{
${ }^{11}$ We could have modelled a more realistic consumption-age profile that is hump-shaped if we had introduced stochastic survival probabilities, uncertain lifetime, or uncertain medical expenditures in old age. We, however, kept the model as simple as possible in order to economize on computational time.
} 
Figure 3: Average labor supply of productivity types

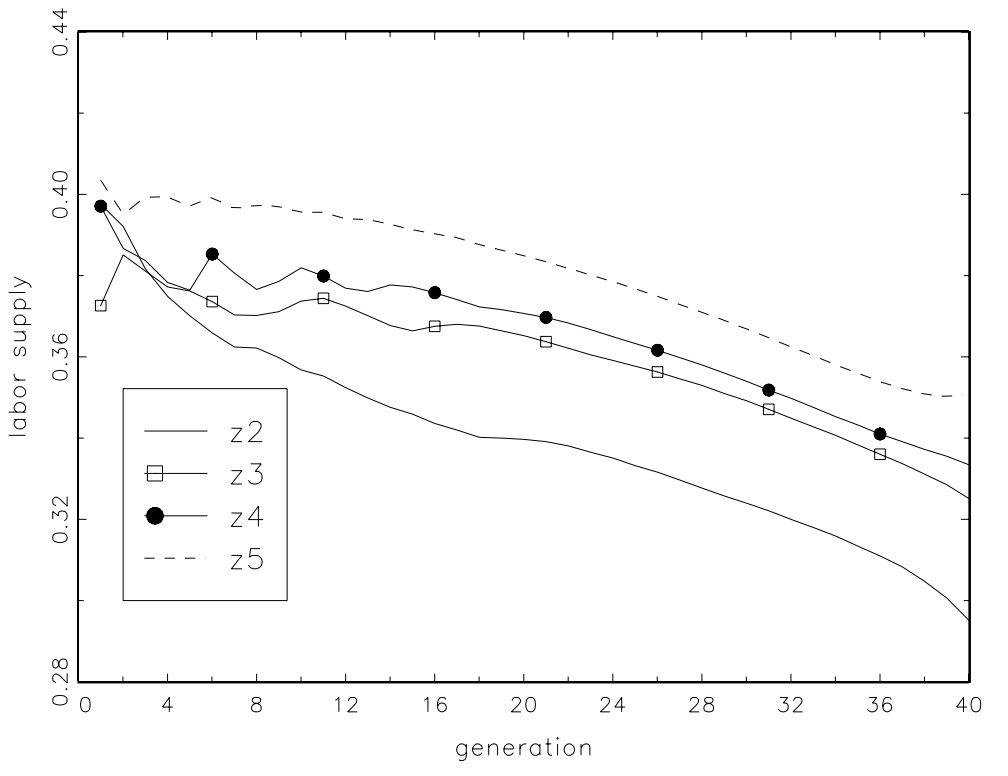

$\tilde{w}$. Accordingly, the higher $\theta$, the more progressive is our system. Total government spending on unemployment benefits remains constant so that an increase of $\theta$ is offset by an equivalent decrease of the lump sum component $w_{\min }$.

There are three effects of an increase in $\theta$ : 1) The incentives of the workers to supply labor increase because they will receive higher benefits in case they become unemployed. This effect is illustrated in figure 4 where we illustrate the average labor supply of each productivity type $\left\{z^{2}, z^{3}, z^{4}, z^{5}\right\}$ for each generation. Obviously, the labor supply increases if we move from a redistributive scheme with $\theta=0.00$ (solid line) to a more contributive scheme with $\theta=0.40$ (broken line). The increase is unanimous and pertinent to all generations and productivity types. 2) Workers with high (low) productivity receive higher (lower) unemployment benefits if they become unemployed. Therefore, the distribution of labor income (including labor replacement income) becomes more unequal. 3) The effect on the capital stock is ambiguous since low-productivity (high-productivity) agents decrease (increase) their savings if they are unemployed, but raise (reduce) their precautionary savings if employed. In fact, if we move from $\theta=0.0$ to $\theta=0.40$, the average capital 
stock of the unemployed workers and the workers with the two lowest productivity types $\left\{z^{2}, z^{3}\right\}$ increases, while it decreases for the workers with high productivity $z \in\left\{z^{4}, z^{5}\right\}$. In particular, the lower three productivity types increase their capital stock by $0.051 \%$, $0.049 \%$, and $0.028 \%$, while the top two productivity types decrease their savings by $0.014 \%$ and $0.016 \%$ on average.

Our results are summarized in table 2. As our main observation, the progressivity of the unemployment benefit scheme has only small effects on equilibrium values of our economy. If we increase the proportionality factor $\theta$ from $0 \%$ to $40 \%$, average labor supply increases by $0.5 \%$. The more progressive unemployment insurance scheme redistributes income away from the low-productivity and younger unemployed workers so that the Gini coefficient of labor income increases from 0.332 to 0.340 . As a consequence, savings also increase by $0.3 \%$ as the effect of the increase in the savings of the low-productivity unemployed workers dominates.

Figure 4: Progressiveness of UI payments and labor supply

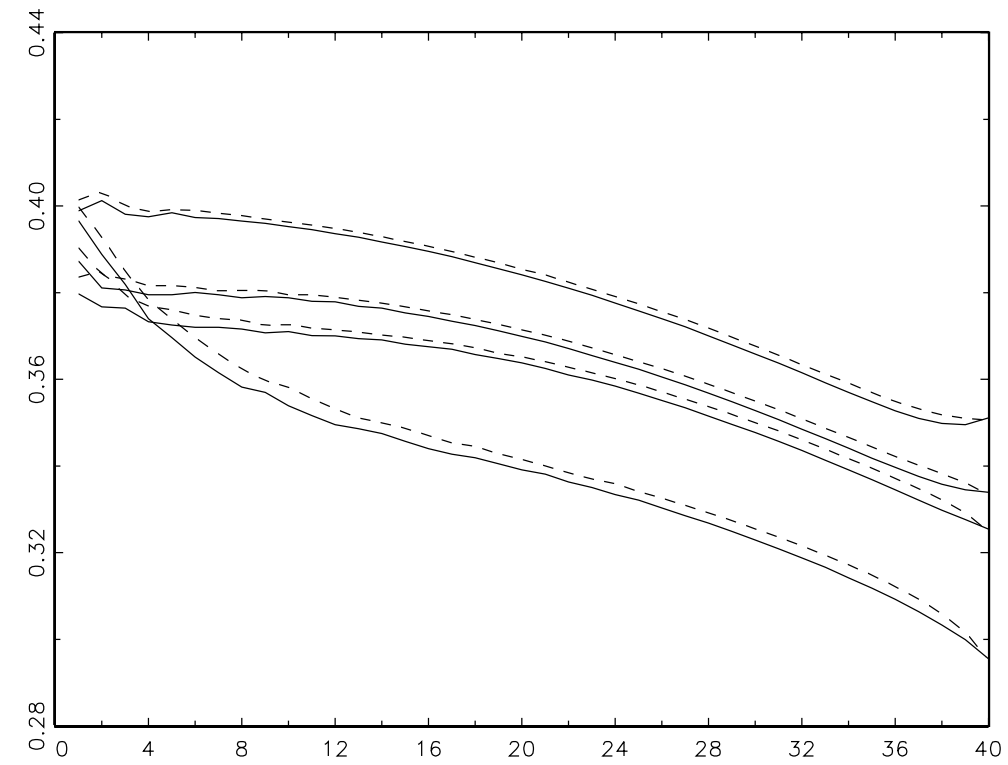

Obviously, a more progressive unemployment insurance system increases the welfare of the high-productivity agents at the expenses of the low-productivity agents. In fact, if we 
move from $\theta=0.0$ to $\theta=0.4$, the value of the newborn workers decreases for productivity types $z \in\left\{z^{1}, z^{2}, z^{3}\right\}$, while it increases for the workers with $z \in\left\{z^{4}, z^{5}\right\}$. In the aggregate economy, agents also increase their savings and supply more labor. These efficiency effects will also improve welfare since, in the present economy, both the accumulation of capital and the labor supply are sub-optimal: The households accumulate too little savings as we specified a lump-sum pension system and the labor supply decision is distorted due to the taxation of labor income. In order to compare the alternative unemployment insurance schemes we need a measure of average utility. As it is common in the literature on computable general equilibrium, we measure welfare by the expected discounted lifetime utility of the newborn generation. The change in welfare relative to the benchmark equilibrium with $\left\{w_{\text {min }}, \theta\right\}=\{0.101,0.20\}$ is computed as the compensation in consumption required in order to make the newborn generation indifferent between the benchmark economy and the economy with the alternative unemployment insurance scheme.

The welfare changes $\Delta_{c}$ are presented in the last column of table 2. The optimal scheme consists of a pure lump-sum payment. Reducing the proportionality factor $\theta$ from $20 \%$ to $0 \%$ while simultaneously increasing the lump-sum component $w_{\text {min }}$ from 0.101 to 0.149 increases welfare by $0.076 \%$ of total consumption. The effect on welfare results from the consideration of different productivity types. ${ }^{12}$ The unemployment insurance system redistributes more income to the unemployed agent with relative little wealth (with former low productivity); in addition, the insurance properties of the system are improved in the sense that the total uncertainty of individual labor income is reduced. Even though this change in welfare seems to be small remember that 1) we kept the total government spending on unemployment compensation constant, 2) only the unemployed workers, who only constitute $10.9 \%$ of all workers, are affected by this measure directly, and 3) households can also insure themselves against the bad luck of unemployment with the help of precautionary savings. We, therefore, carefully interpret our results in the way that it is optimal not to

\footnotetext{
${ }^{12}$ In the working paper version of this paper, we do not consider heterogeneous productivity types. In this scenario, the opposite result holds and the optimal unemployment insurance system is a purely contributive system.
} 
index unemployment benefits to previous earnings.

\subsection{The Hartz IV Reform}

The Hartz IV reform was launched by the German government in 2004 and became effective at the beginning of 2005. Among others, this reform resulted in a limited duration of unemployment benefits equal to 12 months. The level of unemployment benefits remained unchanged. In addition, unemployment assistance ("Arbeitslosenhilfe") and social assistance ("Sozialhilfe") were merged into the new unemployment benefit II ("Arbeitslosengeld II" ). ${ }^{13}$ As the level of "Arbeitslosengeld II" is less than the level of unemployment assistance, the long-term unemployed will receive lower unemployment insurance. In 2006, the monthly payments of "Arbeitslosengeld II" amount to 345 Euro in West Germany and will also rise to this level in East Germany. ${ }^{14}$ Therefore, the replacement ratio of unemployment insurance payments to the long-term unemployed workers (those who are unemployed for more than one year) drops from approximately $50 \%$ to $24 \%{ }^{15}$

In the following, we will compute how this change will affect employment, the distribution of labor income, and welfare. Let unemployment insurance payments be denoted by $w_{U I}=$ $w_{\min }+\theta_{i}(1-\tau) \tilde{w}, i=1,2$, where $\theta_{1}$ and $\theta_{2}$ denote the proportionality factor for the shortterm and long-term unemployed worker, respectively. ${ }^{16}$ As the "Arbeitslosengeld II" is paid lump-sum, we set $\theta_{2}=0$ and calibrate $w_{\text {min }}$ so that the replacement ratio of $w_{\text {min }}$ relative

\footnotetext{
${ }^{13}$ Hunt (1995) and Steiner (1997) provide a more detailed description of the German unemployment insurance system prior to Hartz IV.

${ }^{14}$ For a description of Hartz IV and its effects on the replacement ratio of unemployment insurance please see Althammer (2004).

${ }^{15}$ The replacement ratio of the "Arbeitslosengeld II" is computed with data provided by the Statistische Bundesamt. The average monthly net wage income amounted to 1456 Euro in 2005. Data for 2006 is not yet available.

${ }^{16}$ We refrain from the presentation of a modified version of the model that accounts for this two-tier structure of unemployment insurance. The reformulation of the model is straightforward. In essence, we have to introduce an additional, binary state variable that takes on the value one (zero) if the agent is (not) unemployed for more than one period (=1 year).
} 
to the net wage is equal to $24 \%$. Prior to Hartz IV, the replacement ratio of unemployment assistance was equal to $50 \%$ implying $\theta_{2}=0.26$. For the short-term unemployed, we also set the replacement ratio equal to $50 \%$ implying $\theta_{1}=0.26$ both prior and after the reform. As total expenditures on unemployment insurance decline after Hartz IV, the income tax rate $\tau$ adjusts in order to keep the budget balanced.

Our results for the effects of the Hartz IV reform are summarized in table 3. Obviously, the effects of the Hartz IV reform are very small. The equilibrium values of savings and average labor supply are hardly affected. Even though welfare improves after Hartz IV, the quantitative effect is of small magnitude and amounts to only $0.05 \%$ of total consumption. We also compute the case that the reform would have cut unemployment benefits of the short-term unemployed as well. In the last row of table 3, equilibrium values are presented for the case that also the short-term unemployed workers only receive "Arbeitslosengeld II". In this case, precautionary savings rise and the capital stock increases by $2 \%$. Of course, the distribution of labor income becomes more unequal and the Gini coefficient increases from 0.332 to 0.358 . The effect on welfare is unambiguously positive and amounts to $0.22 \%$ of total consumption. ${ }^{17}$

Table 3: Effects of Hartz IV reform

\begin{tabular}{c|cc|cccccc}
\hline \multirow{2}{*}{ scenario } & & & & & & & & \\
before Hartz IV & 0.0803 & $\{0.26,0.26\}$ & 2.291 & 0.186 & 0.356 & 1.567 & 0.332 & 0 \\
\multirow{2}{*}{ after Hartz IV } & 0.0803 & $\{0.26,0.00\}$ & 2.292 & 0.186 & 0.357 & 1.567 & 0.334 & $0.05 \%$ \\
& & & & & & & & \\
& 0.0825 & $\{0.0,0.0\}$ & 2.332 & 0.186 & 0.357 & 1.576 & 0.358 & $0.22 \%$ \\
\hline
\end{tabular}

At this point, let us mention a word of caution. In our model, we neglect any effects of the unemployment insurance system on the unemployment rate. If unemployment benefits fall,

\footnotetext{
${ }^{17} \mathrm{An}$ additional reduction of the lump-sum component $w_{\min }$ to $5 \%$ of the average net wage with zero contributive rates $\theta_{1}=\theta_{2}$ results in a considerable welfare loss equal to $8.7 \%$ of total consumption.
} 
agents may increase their search effort in order to become re-employed again. In previous work, we have also considered the effects of a two-tier structure of the unemployment system in a model of search unemployment (see Heer, 2003). Different from the present model, however, we did not model different levels of productivity among the workers and only analyzed the case of inelastic labor supply. Therefore, we only considered variation of labor along the extensive margin rather than the intensive margin and neglected redistribution of income among the workers. In Heer (2003) we show that the level of unemployment benefits and unemployment assistance is important for the search effort of the workers and that equilibrium unemployment may fall by approximately $1.0 \%$ if the replacement ratio is reduced by $20 \%$. Therefore, we would like to interpret our results for both total effective hours worked $N$ and welfare that we presented in table 3 as a lower estimate of the true values.

\section{Conclusion}

We analyze the effects of a change in the unemployment insurance scheme from one that pays lump-sum benefits relative to one with benefit payments that are proportional to past contributions. We find that, in the latter case, working hours and savings increase, even though the quantitative effect is small. These efficiency effects, however, have to be contrasted with 1) the distribution effects since such a more contributive unemployment insurance system redistributes income from the low-productivity and young unemployed workers to the high-productivity and older unemployed workers and 2) the insurance effects since the ex ante labor income uncertainty increases. The welfare effect is found to be modest, but unambiguously negative. As a very careful conclusion, we may interpret our results to give support to a lump-sum unemployment insurance arrangement. We also study the likely effects of the Hartz IV reform that reduces unemployment insurance payments to the long-term unemployed. In the German two-tier unemployment system we find that the replacement ratio of long-term unemployment assistance is much less important for the 
individual decision on labor supply than the replacement ratio of unemployment benefits for the short-term unemployed worker. Welfare and efficiency effects of the Hartz IV reform, therefore, are positive but small.

In our analysis, we neglect two important effects of the labor market due to the computational complexity. First, we assume the number of unemployed workers to be exogenous. Of course, if unemployment insurance payments decrease agents search harder for a job and equilibrium unemployment declines. Similarly, the reservation wage falls and unemployment is smaller in the case of wage bargaining. This effect, however, is likely to be small if we only compare different unemployment benefit schemes that keep total government spending on unemployment insurance fixed. In our corresponding working paper (Heer, $2002 \mathrm{~b}$ ) we show this effect to be negligible. In the case of the Hartz IV reform, however, a change in the replacement ratio of unemployment assistance payments is likely to affect the number of unemployed workers. Second, we assume that the household consists of one worker. We neglect any effects resulting from the composition of households. One possible important effect of the indexation of unemployment benefits to previous contributions might result from the consideration of two-person households. Households may be composed of an employed worker and the employed/unemployed spouse. Indexation of unemployment benefits to previous earnings might affect the decision of the spouse to work, e.g., part-time. The incentives to work part-time are increased if unemployment insurance payments are provided lump-sum irrespective of previous contributions. Such a scheme will result in higher total employment, even though problems associated with the moral hazard of the job retention effort will be accentuated as well. 


\section{Appendix: The Solution Algorithm}

The model has no analytical solution. We apply a standard numerical solution method for such kind of heterogenous-agent models with an endogenous distribution and choose value function iteration in order to compute the steady state of the model. ${ }^{18}$ However, we modify the algorithm as follows: Our four-dimensional state space $\{k, \tilde{w}, z, j\}$ consists of two discrete variables, $\{z, j\}$ and two continuous variables, $\{k, \tilde{w}\}$. In order to apply the value function iteration method, we also have to discretize the sub-state space $\{k, \tilde{w}\}$. Therefore, we have to chose a grid of size $n_{k} \times n_{\tilde{w}} \times n_{z} \times\left(T+T^{R}\right)$ over the state space. If we used standard value function iteration, we would have to iterate over all possible next-period values $\left\{k^{\prime}, \tilde{w}^{\prime}\right\}$ and, therefore could only choose a coarse grid over $\{k, \tilde{w}\}$ in order to compute the solution in a reasonable time. Instead, we modify the algorithm so that we can choose a fine grid over $k$ with $n_{k}=1,000$ points. In our modified version, we compute the optimal labor supply $l$ of the $j$-year old household with productivity $z>z^{1}$ and, hence, $\tilde{w}^{\prime}$, from the first-order condition of the household. For $j<T$, this condition is given by:

$$
\gamma_{0}\left(1-l_{j}\right)^{-\gamma_{1}}=c_{j}^{-\sigma}(1-\tau) w \epsilon(z, j)+\sum_{t=j+1}^{T} \pi_{z z^{1}}\left(\pi_{z^{1} z^{1}}\right)^{t-j-1} \beta^{t-j} c_{t}^{-\sigma} \theta(1-\tau) w e(z, j),
$$

where $c_{t}=c_{t}\left(k_{t}, w \epsilon(z, j), z^{1}\right)$ and $k_{t+1}=k^{\prime}\left(k_{t}, w \epsilon(z, j), z^{1}\right)$ are the optimal policy functions of the unemployed at age $t=j+1, \ldots, T$. As we compute the value function recursively starting in period $T+T^{R}$, these policy functions are known. $\pi_{z z^{1}}$ denotes the probability that a worker with productivity $z$ is unemployed during the next period, $\pi_{z z^{1}}=\pi\left(\epsilon^{\prime}=\right.$ $\left.z^{1} \mid \epsilon=z\right)$. Different from the standard first-order condition of the household with respect to labor, (18) contains an additive term on the right-hand side that reflects the effect of the higher working time on the expected future unemployment benefits. As we compute

\footnotetext{
${ }^{18}$ See Heer and Maussner (2005), Chapter 7, for a detailed description on the computation of overlapping generations models with individual or aggregate uncertainty.
} 
the optimal labor supply from the first-order condition, we do not have to iterate over $\tilde{w}^{\prime}$ in our value function iteration.

Our algorithm is described by the following steps:

1. Choose the policy parameters $w_{m i n}, \theta$, and $\vartheta_{b}$.

2. Make initial guesses of $\tau, K$, and $N$ and compute the factor prices $w$ and $r$.

3. Compute the household's decision function by backwards induction with the help of value function iteration.

4. Compute the steady-state distribution of assets, employment, consumption, and labor supply.

5. Compute $N, \bar{l}$, and the average asset holdings of all households from the aggregate consistency conditions.

6. Compute the values $\tau, w$, and $r$ that solves the firm's Euler equations and the government budget.

7. Update $K, N, w, r, \tau$, and $w_{\text {min }}$, and return to step 3 if necessary.

In step 4, the steady-state distribution is computed by forward iteration starting with the 20-year old (corresponding to the 1-period old generation in the model) who has no wealth and no previous income. In addition, the initial distribution of $z$ is given. ${ }^{19}$ The algorithm stops as soon as two successive values of $K$ and $N$ diverge by less than $0.01 \%$, respectively. The Fortran program fa_heer.for can be downloaded from the site http://pro.unibz.it//staff//bheer//.

\footnotetext{
${ }^{19} \mathrm{~A}$ more detailed description of the numerical computation of the stationary distribution can be found in Heer and Maussner (2005).
} 


\section{References}

Acemoglu, D., 2001, Good Jobs versus Bad Jobs: Theory and Some Evidence, Journal of Labor Economics, vol. 19, 1-22.

Acemoglu, D., and R. Shimer, 1999, Efficient Unemployment Insurance, Journal of Political Economy, vol. 107, 893-928.

Althammer, L., 2004, Lehrbuch der Sozialpolitik, 7th edition, Springer: Berlin.

Burdett, K., 1979, Unemployment Insurance Payments as a Search Subsidy: A Theoretical Analysis, Economic Inquiry, vol. 17, 333-43.

Castañeda, A., J. Díaz-Giminénez, J.-V. Ríos-Rull, 2003, Accounting for the US Earnings and Wealth Inequality, Journal of Political Economy, vol. 111, 818-57.

Chiu, W.H., and E. Karni, 1998, Endogenous Adverse Selection and Unemployment Insurance, Journal of Political Economy, vol. 106, 806-27.

Hansen, G., 1993, The cyclical and secular behavior of the labor input: comparing efficiency units and hours worked, Journal of Applied Econometrics 8, 71-80.

Hansen, G., and A. İmrohoroğlu, 1992, The role of unemployment insurance in an economy with liquidity constraints and moral hazards, Journal of Political Economy, vol. 100, $118-42$.

Heer, B., 2002a, The German Unemployment Compensation System: Effects on Aggregate Savings and Wealth Distribution, Review of Income and Wealth, vol. 48, 371-94.

Heer, B., 2002b, Should unemployment benefits be related to previous earnings?, CESifo working paper, No. 747.

Heer, B., 2003, Employment and Welfare Effects of a Two-Tier Unemployment Compensation System, International Tax and Public Finance, vol. 10, 147-68.

Heer, B., and A. Maussner, 2005, Dynamic General Equilibrium: Computational Methods and Applications, Springer: Berlin.

Heer, B., and M. Trede, 2003, 'Efficiency and Distribution Effects of a Revenue-neutral Income Tax Reform', Journal of Macroeconomics, vol. 25, 87-107.

Huggett, M., and G. Ventura, 2000, Understanding why high income households save more than low income households, Journal of Monetary Economics, vol. 45, 361-97.

Hunt, J., 1995, The Effect of Unemployment Compensation on Unemployment Duration in Germany, Journal of Labor Economics, vol. 13, 88-120. 
Ljungqvist, L., and T.J. Sargent, 1998, The European Unemployment Dilemma, Journal of Political Economy, vol. 106, 514-55.

Marimon, R., and F. Zilibotti, 1997, Unemployment vs. mismatch of talents: Reconsidering unemployment benefits, NBER working paper, No. 6038.

Nishiyama, S., and K. Smetters, 2005, Consumption taxes and economic efficiency with idiosyncratic wage shocks, Journal of Political Economy, vol. 113, 1088-1115.

OECD, 1991, Employment Outlook, Paris, July.

OECD, 1996, Employment Outlook, Paris, July.

Shavell, S., and L. Weiss, 1979, The optimal payment of unemployment insurance benefits over time, Journal of Political Economy, vol. 87, 1347-62.

Steiner, V., 1997, Extended Benefit-Entitlement Periods and the Duration of Unemployment in West Germany, ZEW Discussion Paper, no. 97-14, Mannheim.

Stokey, N., J.R. Lucas, and E.C. Prescott, 1989, Recursive methods in economic dynamics, Harvard University Press: Cambridge, MA.

Wang, Ch., and S. Williamson, 1996, Unemployment insurance with moral hazard in a dynamic economy, Carnegie-Rochester Conference Series on Public Policy, vol. 44, $1-41$. 